\title{
Leveraging Students' Passion and Creativity: ETHOS at the University of Dayton
}

\author{
Margaret Pinnell \\ Department of Mechanical and Aerospace Engineering \\ University of Dayton \\ Dayton, OH 45469 \\ mpinnell1@udayton.edu
}

Kevin Hallinan

Department of Mechanical and Aerospace Engineering

University of Dayton

Dayton, OH 45469

khallinan1@udayton.edu

\author{
Malcolm Daniels \\ Department of Electrical and Computer Engineering \\ University of Dayton \\ Dayton, $\mathrm{OH} 45469$ \\ mdaniels1@udayton.edu
}

\author{
Gretchen Berkemeier \\ Department of Mechanical and Aerospace Engineering \\ University of Dayton \\ Dayton, OH 45469 \\ berkemeierg1@udayton.edu
}

Abstract - The Engineers in Technical Humanitarian Opportunities of Service-learning (ETHOS) program was developed in the spring of 2001 by an interdisciplinary group (electrical, chemical, civil and mechanical) of undergraduate engineering students at the University of Dayton (UD). ETHOS was founded on the belief that engineers are more apt and capable to appropriately serve our world if they have an understanding of technology's global linkage with values, culture, society, politics, and the economy. Since 2001, the ETHOS program at UD has grown and changed. From conceptualization, to implementation, to maturation and national recognition, the program has addressed challenges of academic acceptance, programmatic integration and research support as a project-based approach to global engagement. This paper discusses how the program developed from a student idea to a nationally known program. It provides some examples of how projects from this program were integrated into other courses and linked to faculty research. Finally, it will present some of the challenges that face a program such as ETHOS.

Index Terms - Engineering service-learning, community engaged learning, international, cultural immersion, sustainable development, appropriate technology

\section{INTRODUCTION}

Many universities understand the importance and benefit of international service-learning in engineering. A variety of different approaches have been employed to facilitate these experiences. ${ }^{1-21}$ For example, the Marquette University College of Engineering offers a Health, Environment and Infrastructure in Latin America (HEILA) course, where engineering students learn about the history, culture, and politics of Latin America, explore the importance of their major as related to international development, and then participate in a twelve day service trip to a country in Latin America or engage in a service project in the Latino community of Milwaukee. ${ }^{2}$ The School of Engineering at the University of Massachusetts Lowell offers the Service Learning Integrated College of Engineering Program (SLICE) that includes both local and international service-learning projects. The international service-learning projects facilitated 
through the SLICE program are fully integrated into existing courses in several engineering and non-engineering courses available for students at all stages of their academic career. ${ }^{3}$ The Picker Engineering Program at Smith College offers a course entitled Engineering and Global Development, which integrates engineering fundamentals and liberal arts with international service learning. ${ }^{5}$ Baylor offers the Engineers with a Mission program that is made up of undergraduate engineering and computer science students who use their skills to promote appropriate technology in developing communities. ${ }^{6}$ Perhaps the most widely known organization that provides international service-learning opportunities to engineering students is Engineers Without Borders (EWB). In addition to working with students EWB also offers service opportunities for engineering professionals. This program, which was started in 2001 at Colorado University Boulder, has realized explosive growth since its inception and currently has close to 700 community development projects in 39 countries. EWB has student and professional chapters at numerous universities and in many communities both in the United States and worldwide. $^{4}$

In the School of Engineering (SoE) at the University of Dayton (UD), international service-learning is offered through the Engineers in Technical Humanitarian Opportunities of Service-learning (ETHOS) program. This program was developed in the spring of 2001 by an interdisciplinary group of undergraduate engineering students (electrical, chemical, civil, and mechanical). ETHOS was founded on the belief that engineers are more apt and capable to appropriately serve the world if they have an understanding of technology's global linkage with values, culture, society, politics, and the economy. The educational objectives of the ETHOS program are to challenge students to think creatively and independently, to work as a team, communicate effectively, and to address issues of appropriate technology, environmental ethics, social responsibility, and cultural sensitivity. ETHOS seeks to meet these objectives through activities that support the advancement of appropriate technologies for the developing world, and through local and domestic engineering service opportunities. These activities include hands-on classroom projects, on-campus student organization activities and international and domestic internships. ETHOS activities have been developed and facilitated to adhere to a set of core values which include: (1) Appropriate Technology - do more with less, make use of local resources without exploitation, co-create design solutions with the community; (2) Cultural Sensitivity - respect the inherent values of the culture; (3) Partnership - develop relationships, work with the community, spread hope and empowerment; (4) Cultural Immersion - act in solidarity through service, learn with and from the community and (5) Personal Transformation let the world change you.

ETHOS has incorporated research projects into several undergraduate Mechanical and Aerospace Engineering courses. Many of the course-integrated research projects have been related to cook stoves for use in developing communities. Examples of these projects include testing insulative bricks and metal used to construct these cook stoves. In these projects, students performed research to better understand the mechanical behavior of the bricks. More recently, course-integrated projects have addressed issues of corrosion to support global work on cook stove design. These projects have provided students with the opportunity to develop course related skills and skills in project management, teamwork, communication and an understanding of sound and ethical business practice. Additionally, they exposed the students to the social and cultural issues in developing countries. These projects also have provided the students with an opportunity to view engineering as a vocation and to consider the impact of engineering 
decisions on people and the environment. ETHOS related projects have also been incorporated in the capstone design courses through both the Design and Manufacturing Clinic and the Innovation Center. These projects, done in collaboration with an international partner, have ranged from the design of portable laptop charging stations to solar autoclaves for sterilizing medical equipment to stove manufacturing for developing countries and a variety of other appropriate technology projects.

In addition to classroom-based service-learning projects, ETHOS provides servicelearning opportunities to engineering students through an on-campus student organization, the ETHOS club. The main objectives of this club are to promote awareness of global technical issues and the effect of technology on societies and cultures in developing communities. ETHOS club activities have included club meetings, on-campus demonstrations on appropriate technology, guest lecturers, field trips, domestic and international alternative spring breaks and sponsorship of awards for local and state high school and junior high science fairs.

A primary role of the ETHOS program is to offer technical service-learning internships to engineering students with organizations in developing countries that are involved in appropriate technology, sustainable development and education. Since its inception in 2001, over 240 students have traveled to 19 countries to work with partner organizations and communities to assist in finding appropriate, sustainable and effective solutions to technical challenges while gaining a better understanding of the global interaction of technology and society. ${ }^{22}$ In the fall of 2003, a one to three credit hour course was approved as an elective by the SoE which enables students to earn academic credit for preparing for and participating in an ETHOS internship. This service-learning course, which includes a project-based introduction to appropriate technology design, targeted language preparation, selected readings and discussions on appropriate technology development and cultural immersion, independent project research and a summer service-learning immersion focused on technical or engineering related work in a developing country, spans the winter and summer semesters.

\section{ETHOS - AN EXAMPLE OF "APPROPRIATE TECHNOLOGY"}

The establishment and success of the ETHOS program is largely attributed to its organic roots and its alignment with the mission of the university. UD is a midsized Catholic university that is "committed, in the Marianist tradition, to educating the whole person and linking learning and scholarship with leadership and service." 23 UD has a long tradition of local, domestic and international service through its Campus Ministry, Center for Social Concern, Fitz Center and Center for Catholic Education, as well as through numerous service-learning projects offered in various courses. The Marianists have both a local and international presence that has been leveraged in the development of a majority of these service programs. Additionally, service at UD is strongly influenced by the five characteristics of a Marianist education which address: education for formation in faith; an integral, quality education; education in the family spirit; education for service, justice, peace and integrity of creation and education for adaption and change. As such, building community and sustainable relationships are key aspects of service done at UD. The development of ETHOS was greatly influenced by these factors. As such, it still has a strong emphasis on relationship and community building.

ETHOS was developed in a very organic manner as the result of a student's passion and persistence with input from key stakeholders, i.e. other students, faculty, staff and community 
partners. An undergraduate Mechanical Engineering student had participated in an international service immersion placement in India, sponsored by the University's Campus Ministry program. Although this student felt the immersion was a wonderful experience, she was convinced that other engineering students at UD should have the opportunity to serve internationally as she did. Further, she was frustrated about the lack of an opportunity to apply her engineering skills and knowledge in support of people in the developing world. This student approached the chair of the Mechanical Engineering Department at the time with these concerns. The department chair challenged this student to develop a service-learning immersion program specifically for engineers as her capstone design project. The student then reached out to other students from all engineering disciplines to form a design team. This multi-disciplinary team then used the engineering design process to develop an international engineering service-learning program, distinctive of the foundations of UD and its Marianist charism.

As part of the design process, the team did a significant amount of research to determine global needs, gain a better understanding of appropriate technology and identify other organizations and university programs that were currently engaged in international engineering service. Part of the research the students conducted included identifying and studying similar programs already in existence (at that time EWB was just being formed). They also leveraged the vast local service-learning project experience of UD. In developing the ETHOS program, the founding students consulted greatly with a Marianist Brother who ran the immersion programs through Campus Ministry. This Brother cautioned the students about "serving" as opposed to "learning" and the potential for service-projects to have negative effects (economical, selfsufficiency, cultural) on the community being served. The president of UD at that time, also shared his great wealth of experience relative to community engagement and encouraged the students to develop a program that would help strengthen and empower the community being served. The students took this advice in developing the foundations of ETHOS which were later articulated through the five core values described above. In addition to developing a mission and vision for the ETHOS program, the student team also developed the logistics of the program. They worked with UD's Campus Ministry to adapt an existing immersion preparatory shortcourse to meet the needs of the engineering students who would be participating in this program. The preparatory short-course included language training, travel safety and health information, and cultural sensitivity training. At the conclusion of the design effort, the student team had established the program's name and acronym, mission, immersion process requirements, and made initial placement contacts with partner organizations.

During the first several years of the program, academic credit was not awarded to the students participating in the engineering service immersions. Furthermore, only 5-10 students participated in the international immersion placements each year. Most of the travel arrangements and preparatory sessions were coordinated by graduate assistants who were loosely under the guidance of a Mechanical Engineering faculty member and the department chair. The graduate assistant was partially funded through the Mechanical Engineering Department, but also had a research assistantship with a faculty member. Funding for student travel was provided by various internal funding sources including the SoE, Campus Ministry, the Chaminade Scholar Program and the New Engineer Program, and through personal and group fundraising efforts.

As the program grew, the role of the volunteer faculty advisor/director also grew. As the program began to receive national attention, the administration recognized it as a potentially distinguishing program as well as a program that was very well aligned with the mission of the 
university. Additionally, the administration realized ETHOS to be a powerful student recruitment tool and as a way for UD engineering students to gain international experience and have a transformative experience. As such, the Dean of the SoE provided both financial support and personnel to assist with the program. The faculty director continued to work with the graduate assistants to develop an elective course that formalized the preparation process, created a clear definition of the student deliverables and provided participating students with academic credit. The ETHOS administrative team made up of the faculty director, graduate assistant with input from campus ministry and other campus resources developed forms and other student paperwork, created a handbook for the course and advertising brochures and recruitment events. The team also wrote proposals to seek external funding for the program, conducted research and wrote papers on service-learning, engineering education, appropriate technology and international education, participated in workshops and conferences and made other efforts to collaborate and communicate with other professionals involved in similar work. Eventually, the newly appointed SoE service-learning coordinator was added to the ETHOS administrative team.

As student interest grew, an on-campus club was developed to provide awareness about global engineering issues, to inform students of appropriate technology and to provide local service-learning opportunities for engineers on a smaller scale. The ETHOS club organized various activities such as club meetings, on-campus appropriate technology demonstrations, a guest lecture series, field trips, collaboration with community organizations, and local, district and state junior and senior high school science fair award sponsorship. The ETHOS club strives to attract first and second year students as many of the other aspects of the ETHOS program are not available until after the sophomore year. The major operation of the club is to support projects occurring on campus as well as serve as exposure of the program to the student body.

The ETHOS program receives financial support from a variety of sources. The cost to send a student on a technical immersion is in the range of $\$ 2,000-\$ 5,000$. Additional costs, such as supplies, educational materials, administrative costs, mailings, and various events and activities, are also incurred to support this program. Although the students are not expected to pay anything to participate in these immersions, each student is expected to raise $\$ 1100$ through family letters and by participating in group fund raisers. Additional financial support for their travels is provided by the various university sources, the UD SoE, private and corporate donations.

As ETHOS evolved, it grew to rely upon five main campus partners. The Center for International Programs (CIP), which has a long history in managing student learning abroad programs, provides administrative support. The CIP assists the ETHOS students by providing passport seminars, travel information, and safety material. Additionally, the CIP oversees all student travel, keeps a database of traveling students and facilitates an emergency response team. The travel agency on campus provides assistance to the students in arranging flights and other travel details. UD and University of Dayton Research Institute (UDRI) faculty and staff encompass provide ETHOS participants with technical support in preparation for and during their technical immersions. Support for language preparation is provided through the Language Department's Language Lab. The fifth campus partner is the campus health center, which provides assistance with vaccinations and other health related issues. 


\section{ETHOS INTERNATIONAL IMMERSIONS}

As mentioned above, the central component of the ETHOS program, is and continues to be, ETHOS international immersions. Undergraduate students earn academic credit towards their engineering degrees by preparing for, participating in and documenting their ETHOS experience by taking the mandatory one to three semester hour course: Engineering Design and Appropriate Technology. Students can participate in more than one technical immersion trip, but typically do not receive additional academic credit. However, those students who wish to embark on a second immersion are still required to participate in all aspects of the course. The technical immersions are also available to graduate students, but typically they do not receive academic credit for their participation unless special arrangements are made with a faculty member to accommodate this. The Engineering Design and Appropriate Technology course spans three semesters. During the spring semester, students participate in the immersion preparation course. In this course, they learn about appropriate technology and cultural immersion. Additionally they are encouraged to pursue language preparation. The cultural immersion portion of the course covers very important and practical information associated with international travel such as cultural sensitivity, passports, vaccinations and health issues, packing tips, safety and other issues associated with travel. Time is permitted in class for organizational meetings, placement information, an introduction to appropriate technology and hands-on technical training. The specific methods used to facilitate the technical preparation portion of the course has changed from semester to semester depending on the faculty member facilitating the class, but typically includes both independent or group research and hands-on laboratory activities. The students are also required to participate in additional appropriate technology activities, demonstrations and lectures.

The ETHOS international technical service-learning immersions have almost exclusively taken place during the summer semester. Students travel in small teams of two to three students each and typically live individually with host families. The ETHOS immersions are typically ten weeks in length, during which time the students work with collaborating organizations and communities to assist in finding appropriate, sustainable and effective solutions to technical challenges through guided research, development, and projects. Since the students are placed with organizations and NGO's that are involved in ongoing research and development work and have an onsite technical director, the students are able to contribute individually or as a team to an ongoing project in the short amount ( 10 weeks) of time that they are at their placement. In many instances, the students have continued to work on these projects upon their return to UD then participate in an immersion the following summer at the same placement site. During the fall semester, students return to campus write a technical report summarizing their work, write a reflection report, attend a dissemination dinner or poster presentation, attend a retreat and participate in many other activities to reflect on and share their experiences.

Working with organizations that have a defined presence in the community, the length of the placement and the student team size are key aspects of the ETHOS program as these program elements help to ensure that the students become fully immersed in the community and develop relationships with the community members. Furthermore, by working with existing community organization sustainability of the projects after the students depart is ensured. Success of the ETHOS program relies heavily on well-established international partners. Since the ETHOS program sends students to the same placement sites for multiples years, there is a clear understanding between the ETHOS program and the international partner about the 
responsibilities of the various stake holders. For instance, the international partner identifies suitable host families and sets up the payment structure for the room and board. Most of the well-established international partners are located in rural villages and small towns. Students typically describe the people in these communities as "poor." During their stay, students live with a host family and interact with members of the community on a daily basis. The ETHOS administration stresses to the students the importance of establishing relationships in the community and learning with the community. Part of the reason why the students are sent in small teams as opposed to large teams is that this type of an arrangement encourages the students to completely immerse themselves in the community and to establish a close relationship with their host family and the community. With the help of the host organization and community, students are able to use their engineering knowledge to address real world problems, while gaining a better understanding of the interface between technology and the global society.

\section{EXEMPLAR STUDENT EXPERIENCE}

The ETHOS program has benefited from faculty initiatives that integrate ETHOS project related research, assignments or project work in various classes. Examples of courses that have incorporated ETHOS projects as part of their assignments or curriculum include Engineering Innovation (first year engineering course), Introduction to Materials, Heat Transfer, Experimentation, Honors Thesis special problems courses and capstone design. In an ETHOS strategic plan developed in 2009, an integrative program was proposed where ETHOS would be infused across the engineering curriculum with supporting classes offered as part of the newly designed general education program at UD. Although this plan has not yet been realized, ETHOS has benefited from several instances where a student or team of students took the initiative to more fully integrate their ETHOS experience in their other courses. One example of this was the solar sterilizer project.

During the summer of 2006, a sophomore undergraduate engineering student at UD participated in an ETHOS immersion. During this immersion, she worked in Nicaragua for eight weeks on an assortment of solar projects. She also had the opportunity to interact with the local community on a daily basis and gain an understanding of some of the needs of the community. Having worked for a medical device company the previous semester, this student identified the need for a local clinic to have access to an effective, but inexpensive way to sterilize small medical devices. The student observed that the clinic had no means of sterilizing the equipment on site. Because of this, the head nurse of the clinic had to travel a great distance by bus in order to sterilize the equipment. The process of taking the medical equipment to be sterilized took a significant amount of time and money. Although the clinic had access to electricity, they did not have an electric sterilizer nor did the clinic have the money to pay for the use of electricity to run an electric sterilizer. Through these observations and in consultation with other professionals at this organization, the student identified the need for a medical device sterilizer which could be powered by renewable resources such as direct solar power. Equipment such as this would greatly enhance the ability of the local community to provide health care to its residents.

Upon the student's return to UD, she began doing some research on solar sterilizers. Through her research, she found that solar sterilizers exist, but could benefit from design improvements. Furthermore, there was an interest in the Nicaraguan community she worked in to develop micro-businesses that would provide work for the residents and help to enhance the economy of the local community. To facilitate the design and development of the solar 
sterilizer, the student undertook the research required to fully understand solar technologies and medical sterilization as her undergraduate thesis topic. Additionally, various aspects of this research were integrated as class projects in two required undergraduate mechanical engineering courses, Thermodynamics and Experimentation Lab. A bulk of the design and development work was done through the two semester capstone design course that is facilitated through UD's Design Clinic. The technical goals of this project were to research, design, build a prototype and test a solar sterilizer that could be used in a rural community in Nicaragua. The design was developed with the input and assistance of the head nurse of a medical clinic in Nicaragua and the international partner, Grupo Fenix. Initial development of candidate designs, development of an on-site test protocol and building of a prototype occurred in the winter semester of 2008 as part of the first course of a two semester capstone design class. A team of five undergraduate mechanical engineering students worked on this project. The team consisted of the lead student who had originally identified the project and who had done the initial research for her undergraduate thesis, a student who would travel for the first time to Nicaragua in the summer of 2008, and three additional mechanical engineering students. The deliverables for the first part of this course included several design plans, a test schedule and test protocol developed through some preliminary laboratory testing, a prototype and report.

A business plan for transferring the technology to develop a micro-business in the Nicaraguan community was developed as part of the Business Plan Competition (BPC) which is run through UD's School of Business Administration. The solar sterilizer business plan team, Salud del Sol, consisted of two undergraduate engineering students and two undergraduate business students. The engineering students that were part of this team included the lead student and another member of the Design Clinic project team. The student team won first place in the BPC and started Salud del Sol. This "company" has hosted UD students participating in ETHOS immersions in Nicaragua.

Although this project strove to address a particular technical need, the infrastructure, longitudinal course integration, interdisciplinary approach and unique partnerships that were developed and nurtured through its facilitation have served as a model for other ETHOS projects. In particular, the integrative nature of the project provided a deep and meaningful educational experience for the participating students. The lead student was able to weave various aspects of the solar sterilizer project into many aspects of her educational experience starting from the second semester of her sophomore year when she worked for the medical device company. From this experience, she was able to identify the need for the solar sterilizer when she participated in her first service-learning immersion experience through the ETHOS program. She also incorporated this project into her undergraduate research topic, chose classes related to this project as her technical electives, participated in the BPC, and served as the lead student for the Design Clinic project team. Being able to have a continual focus for research and classes provided the lead student with an opportunity to apply concepts learned from a variety of courses as well as skills she gained through work experience, independent research and her international experience to a single project. 


\section{A Summary OF THE ASSETS OF ETHOS}

Some of the key assets of the ETHOS program include:

- Student participation in well-established cultural immersion, language and technical preparation;

- Well established partnerships with organizations that provide meaningful research and development projects and on-site mentorship for students in all engineering disciplines;

- Funds to support travel costs through alumni donations and support from the university.

- Integrated classroom projects providing participating students with the opportunity to continue their research and engage other students in their research upon their return;

- An academic program developed by students, for students and largely managed by students;

- Small team immersions to manage risk and enhance the safety and security of participants;

- An individual living and learning experience with host families which enhances their cultural immersion experience;

- An extended educational experience for a minimum of ten weeks which assists students in becoming proficient in a foreign language and allows them to engage in "long" term appropriate technology research projects;

- Community engaged learning at home and abroad; building a shared experience through student collaborative fund-raising and preparation class activities;

- Curriculum linkage to ETHOS which enables students to leverage their participation to meet academic program requirements.

\section{CHALLENGES}

During the thirteen years that ETHOS has been in existence it has experienced tremendous success and growth as well as many challenges. Although growth is generally perceived to be very positive, it has also challenged many of the program expectations and capabilities. Over the years, many students have reported that the ETHOS program is one of the main reasons they chose to come to UD. Student interest remains strong, with over 60 students applying to participate in the fall of $2013 .^{22}$ Since student travel is heavily subsidized by the SoE, and staffing resources limit the number of partner sites that can be identified, nurtured and maintained, the program can generally only accommodate 30 participants each summer.

The second challenge has been leadership. As program growth challenged student capacity to facilitate and lead both the academic and immersion program, the program relied increasingly on voluntary leadership from faculty and staff. Not surprisingly, support from the Dean of the SoE and other leaders on campus became a critical issue. Financial support has been instrumental in sustaining the program and must be part of the main SoE budget and supplemented through institutional development and fundraising. Additionally, broader faculty engagement across all engineering disciplines remains largely unrecognized and unrewarded both financially and in terms of promotion and tenure. Leadership challenges remain and are closely coupled to institutional leadership. To advance the program and ensure long term institutionalization, base budget funding is necessary. Program costs are not insignificant and constitute the major barrier to expansion and the development of similar programs at other institutions. For ETHOS to remain an organization committed to 'exemplar projects' and 'deep' intercultural engagement 
with international community partners then stable funding mechanisms, a close relationship with supporting university agencies such as the CIP and institutional support at all levels are required. Without this, the ETHOS program runs the risk of becoming simply an international travel program for engineering students that lacks connectedness with their academic pursuits. Furthermore, if this is done, the ETHOS program runs the risk of straying from its core values and from effectively supporting the mission of its international community partners.

\section{RECOMMENDATIONS}

Although there are tremendous benefits associated with engaging engineering students in international development projects, one should proceed with caution when developing a program such as ETHOS. The most important recommendation is to make sure that programs are cocreated with key stakeholders. Among these key stakeholders include the international communities and community partners, faculty, staff (international program staff, health and safety, appropriate administration, etc.) and students. The co-creation process will help to ensure that the program meets the needs of all those involved and is therefore, more likely to be successful. A second recommendation is to make sure that the program mission is well aligned with the mission of the engineering school or department as well as with the mission of the college or university. When a program is well aligned with the mission of the department, college and/or university it makes issues associated with fund-raising, faculty and student involvement and administration buy-in much easier. A third recommendation is to identify international projects that align well with faculty research interests. This will help to ensure that engineering faculty can be involved in the program and projects without compromising their own research agenda or becoming distracted in a manner that might jeopardize their ability to get tenure and promotions. Additionally, a scholarly approach should be taken towards the pedagogy of service/civic engaged learning for both the benefit of the faculty involved in the program and the program as a whole. Some final recommendations are to start small and leverage the assets of the department and university such as centers for international programs, health center, development office and risk management. 


\section{REFERENCES}

1 “ECOS, " http://ecos.osu.edu/taxonomy/term/2, accessed 14 Jan 07.

2 "Marquette University," http://www.marquette.edu/engineering/pages/AllYouNeed/international.htm accessed 14 Jan 07.

3 “SLICE," http://www.slice.uml.edu, accessed 25 Sept 14.

4 “Engineers without Boarders," http://www.ewb-usa.org, accessed 25 Sept 14.

5 D. Riley and A.H. Bloomgarden," "Learning and Service in Engineering and Global Development," International Journal for Service-Learning in Engineering, 2:1, (2006): 48-59,.

6 "Baylor University," http://www.baylorem.org/, accessed 15 Sept 14.

7 S. Scheibler, "Creating a "Global Algorithm" for Engineering Education," Proceedings of the 2006 ASEE Annual Conference and Exposition, (2006).

${ }^{8}$ H. L. Wakeland, "International Education for Engineers: A Working Model," ANNALS, AAPSS: (1990): 511.

9 E. Doerry, K. Doerry, B. Bero, "Providing an Integrated International Experience for Undergraduate Engineering Students at a Small Institution," Proceedings of the 2006 ASEE Annual Conference and Exposition, (2006).

${ }^{10}$ R. Gordon, A. Gordon, P. Bedient, "Rice University Engineers Without Borders: An Exercise in International Service Learning," Proceedings of the 2006 ASEE Annual Conference and Exposition, (2006).

${ }^{11}$ M. Frank, I. Lavy, D. Elata, "Implementing the Project-Based Learning Approach in an Academic Engineering Course," International Journal of Technology and Design Education: 13, (2003): $373-$ 288.

${ }^{12}$ A. Pérez-Foguet, S. Oliete-Josa, A. Saz-Carranza, "Development Education and Engineering: A Framework for Incorporating Reality of Developing Countries into Engineering Studies," International Journal of Sustainability in Higher Education, 6:3,(2005): 278-303.

${ }^{13}$ R. Husfeld, C. Polito, E. Gingerich, " Lessons Implemented on an International Service Learning Project," Proceedings of the 2006 ASEE Annual Conference and Exposition, (2006).

${ }^{14}$ D.E. Mason, et. al., "Innovation in a Large-Scale Study-Abroad Program in Engineering," Proceedings of the 2004 ASEE Annual Conference and Exposition, (2004).

${ }^{15}$ E. Johnson, S. DeMaris, D. Tougaw, "Providing an Integrated International Experience for Undergraduate Engineering Students at a Small Institution," Proceedings of the 2006 ASEE Annual Conference and Exposition, (2006).

${ }^{16}$ E. Tsang, Projects that Matter: Concepts and Models for Service Learning in Engineering, AAHE, Washington D.C., (2000).

${ }^{17}$ J. Duffy, "Service Learning in a Variety of Engineering Courses, Projects that Matter: Concepts and Models for Service Learning in Engineering," AAHE, E. Tsang, ed., Washington D.C., (2000).

18 "EPICS," http://epics.ecn.purdue.edu, accessed 17 Sept 14.

${ }^{19}$ K. Paterson, et.al., "International Service Engineering Across Academic Borders," Proceedings of the 2006 ASEE Annual Conference and Exposition, (2006).

${ }^{20}$ J. Lucena, G.L. Downey, “ Engineering Cultures: Better Problem Solving through Human and Global Perspectives," Proceedings of the 1999 ASEE Annual Conference and Exposition, (1999).

${ }^{21}$ P.T. Martin, and J. Coles, "How to Institutionalize Service-Learning into the Curriculum of an Engineering Department: Designing a Workable Plan, Projects that Matter-Concepts and Models for Service-Learning in Engineering, AAHE, E. Tsang, ed., Washington D.C., (2000).

22 "ETHOS," https://www.udayton.edu/engineering/ethos/, accessed 25 Sept 14

23 "University of Dayton," http://www.udayton.edu, accessed 25 Sept 14.

24 "Marianist", http://www.marianist.com/ accessed 25 Sept 14. 